\title{
Ileo-uterine fistula after dilatation and curettage: Case report
}

\author{
Dr Manish Kumar Singh Dr Alok Kumar Dr Prof Subrata Nag
}

\begin{abstract}
Ileo-uterine fistula is a very rare occurrence. In this case we presented a case of ileo-uterine fistula, which developed after dilatation and curettage for termination of pregnancy.The case was managed surgically.
\end{abstract}

\section{Introduction}

Entero-uterine fistulas have rarely been described complications of curettage procedures. We describe a case report of a ileo-uterine fistula, which formed after dilatation and curettage for termination of pregnancy.

\section{Case Report}

A 25 years old female presented with per vaginal discharge for last 6 months. Six month back patient had undergone for dilatation and curettage for termination of 3 months old pregnancy. On examination mild pallor was present.Systemic examination was within normal limit. P/V examination revealed continous greenish discharge through cervical opening, no any vaginal fistula found. On the basis of history and examination provisional diagnosis of entero-uterine fistula made and planned for exploratory laparotomy.The patient underwent exploratory laparotomy, in which small bowel loops were found to be densely adherent to the fundus of the uterus. Dissection of the small bowel from the uterus revealed a ileo-uterine fistula between a loop of ileum( approximately $25 \mathrm{~cm}$ proximal to ileo-cecal region) and the uterine fundus (Figure 1). The uterine funduss appeared necrotic and ruptured in the midline, appearing as a wedge-shaped defect. The ileum involved in the fistula was resected and intestinal continuity was reestablished with a primary small bowel anastomosis and also repaired uterine fundus(Figure2). Postoperative course was unremarkable.

\section{Discussion}

A fistula is an abnormal connection between two epithelium-lined organs or vessels that do not connect. In the case of the uterus, fistulas can develop to the bladder, colon, and small intestine. Enterouterine fistulas occur infrequently. Martin et al. ${ }^{1}$ published perhaps the largest review of enterouterine fistulas in 1956 which described 80 cases, 42 of which, followed obstetric injury, 17 resulting from inflammatory processes, 12 following curettage, and 9 related to carcinoma.

In particular, ileo-uterine fistulas are rare. McFarlane et al. ${ }^{2}$ described a jejuno-uterine fistula that developed two weeks after dilatation and curettage performed for severe postpartum hemorrhage. Duttaroy et al. ${ }^{3}$ described symptoms of a jejuno-uterine fistula developing 3 months after dilation and evacuation for a spontaneous abortion. Singh et al. ${ }^{4}$ described a chronic jejuno-uterine fistula following termination of pregnancy, discovered after 3 consecutive abortions. Vohra et al. ${ }^{5}$ described a jejuno-uterine fistula occurring 6 weeks after curettage for retained products of conception. Simon D. Eiref et al. ${ }^{6}$.described Jejuno-Uterine Fistula after Endovascular Embolization For Uterine Bleeding All cases were managed by surgical repair.

In this case patient developed ileo-uterine fistula after dilatation and curettage and presented with $\mathrm{p} / \mathrm{v}$ discharge. Management of ileo-uterine fistula has traditionally been surgical involving resection of the fistula

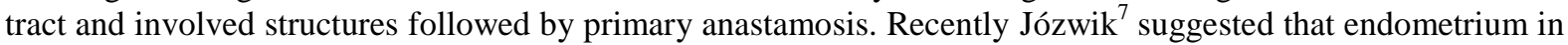
the fistula tract may be amenable to hormonal regulation and therefore conservative treatment. Our surgical approach was similar to ones described by McFarlane, Duttaroy, and Martin.

\section{Disclosures}

The authors have no disclosures or conflicts of interest related to this manuscript.

\section{References}

[1]. Martin DH, Hixson CH, Wilson EC Jr. Enterouterine fistula; review; report of an unusual case. Obstet Gynecol. 1956 Apr;7(4):4669.

[2]. McFarlane MEC, Plummer JM, Remy T, Christie L, Laws D, Richard H, Cherrie T, Edwards R. Coward C. Jejunouterine fistula: a case report. Gynecol Surg (2008) 5:173-175.

[3]. Duttaroy D. Jejuno-uterine fistula. European Journal of Obstetrics \& Gynecology and Reproductive Biology 129 (2006) 92-99.

[4]. Singh RB, Pavithran NM, Parameswaran RM, Sangwan K. Chronic jejuno-uterine fistula: an unusual cause for recurrent second trimester abortions. Aust N Z J Obstet Gynaecol 2005 45(6);533-534.

[5]. Vohra PA, Kumar Y, Raniga S, Vaidya V, Verma S, Mehta CA Case Of Jejunouterine Fistula Ind J Radiol Imag 2005 15:4:427428. 
[6]. Eiref SD, Holekamp S, Koulos J, Levi G, Winestone M, Kagen A, and Leitman IM. Jejuno-uterine fistula after endovascular embolization for uterine bleeding. J Surg Radiol. 2010 Oct 1;1(2).

[7]. Józwik M, Józwik M.Hormonal dependence of fistulas communicating with the uterus. Int Urogynecol J Pelvic Floor Dysfunct. 2007 Jul;18(7):719-20. Epub 2007 Mar 27.

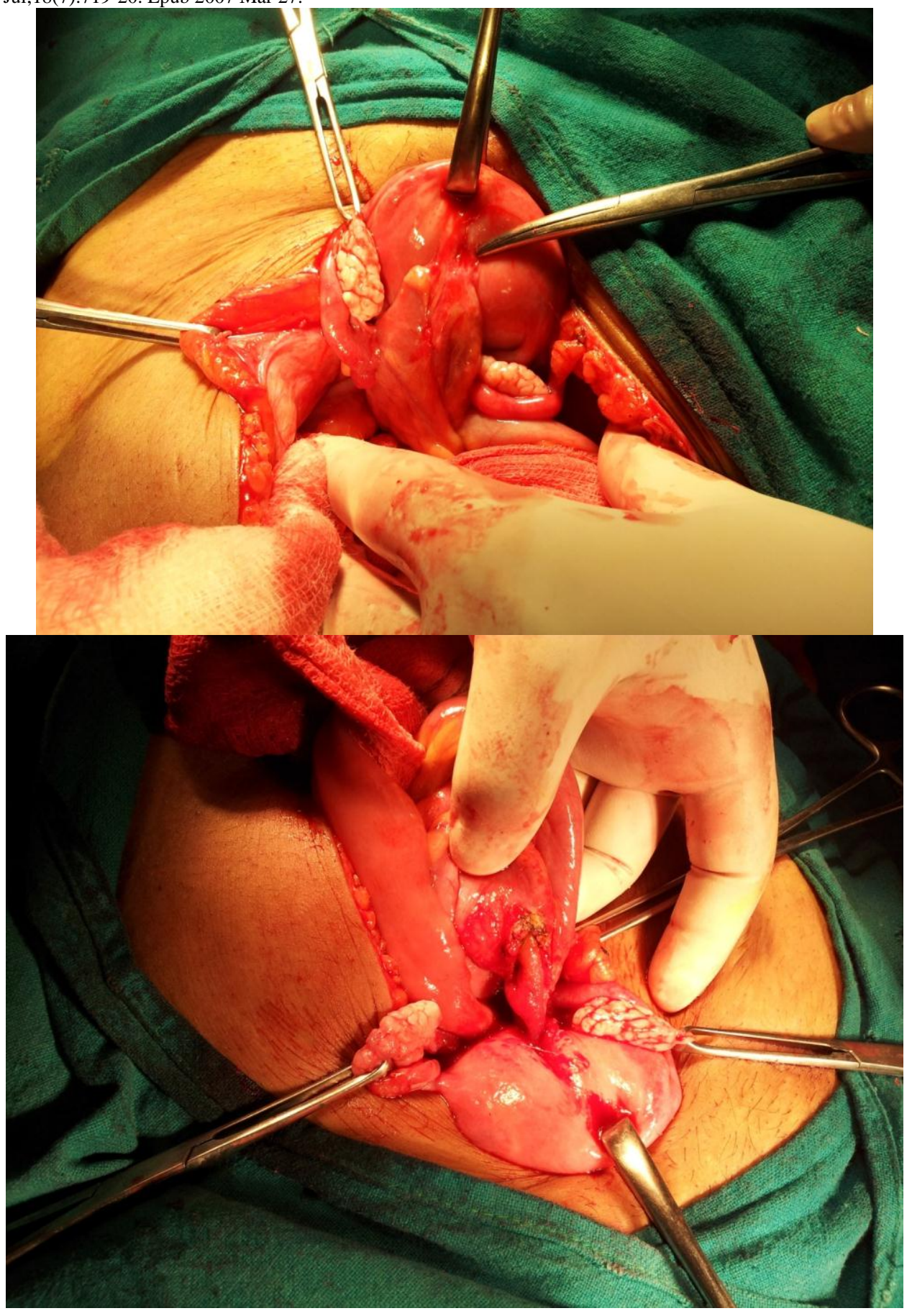

